\title{
Estudio comparativo de la morfología de huevos en Tettigoniinae (Insecta: Orthoptera) de Chile, mediante una aproximación con SEM
}

\section{A comparative study of the eggs morphology in Tettigoniinae (Insecta: Orthoptera) of Chile, using a SEM approach}

\author{
Alejandro Vera Sánchez $Z^{1}$ \\ 1Depto. Biología, Universidad Metropolitana de Ciencias de la Educación. Av. José Pedro Alessandri № 774, Ñuñoa, Santiago, \\ Chile. \\ E-mail: alveras2@gmail.com
}

\begin{abstract}
RESUMEN
La morfología coriónica de huevos, para cuatro géneros de la tribu Nedubini presentes en Chile, se estudia de forma comparada, tres de estos géneros son endémicos. Se describen los huevos para las especies Barraza cribeloplatus, Xyrdectes fuscens, Falsidectes divisus, Platydecticus onax, P. pheroxyfus, P. robertsi y $P$. sp. Las observaciones fueron realizadas con microscopía óptica y SEM. Los huevos de Nedubini para la Región Andina de América del Sur son descritos por primera vez, los resultados muestran que la morfología de las celdas coriónicas y de las micropilas son informativas para diagnosticar géneros y especies.
\end{abstract}

Palabras Claves: Biodiversidad, Corion, Especies crípticas, Nedubini, Taxonomía.

\begin{abstract}
The morphology of chorionic eggs for four genera of the tribe Nedubini present in Chile, is studied in a comparative way, three of these genera are endemic. Descriptions of the eggs of seven species are given, Barraza cribeloplatus, Xyrdectes fuscens, Falsidectes divisus, Platydecticus onax, P. pheroxyfus, P. robertsi \& P. sp. The observations were made with optical microscopy and SEM. Nedubini eggs for the Andes Region of South America are described for the first time, the results show that the morphology of the chorionic cells and micropyles are informative to diagnose genera and species.
\end{abstract}

KeYworD: Biodiversity, Chorion, Cryptic species, Nedubini, Taxonomy.

\section{INTRODUCCIÓN}

La morfología coriónica de los huevos de Insecta proporciona en muchas taxa rasgos relevantes para la sistemática e identificación. Grupos tradicionalmente estudiados en este sentido se encuentran en Polyneoptera como Plecoptera (Stark 2009), Ephemeroptera (Domínguez et al. 2006) y Phasmatodea (Zompro 2004) donde la morfología de los huevos ayuda incluso a discriminar especies crípticas. En otros grupos relacionados a faenas agrícolas y forestales como son Lepidoptera y Orthoptera, se han desarrollado herramientas de diagnosis en base a morfología de huevos, estas son relevantes para identificar plagas como ocurre con algunos Acrididae (Tunck \& Smith 1939, Ganguly et al. 2008).
En la actualidad es frecuente que el trabajo taxonómico en Orthoptera incluya junto a las descripciones de nuevas taxa la morfología de sus huevos, contribuyendo con rasgos informativos en la discriminación de especies (Webber et al. 2007), así como en la asignación de otras taxa como las tribus (Rentz et al. 2007).

La morfología de huevos en Tettigoniidae Krauss 1902 varía de acuerdo a las características de los sustratos de ovipostura y al grado de exposición ambiental, durante el desarrollo embrionario. En algunas especies la diapausa en estado de huevo puede ser de largos períodos, donde la interacción con factores abióticos como el fotoperíodo, humedad, temperatura y disposición de oxigeno influyen en su duración (Ingrisch 1984, 1985, 1986a, b y c, 1987a y b). Los huevos en Tettigoniidae son puestos individualmente o 
en grupos sin ningún revestimiento adicional que constituya una ooteca, esta condición los deja aún más expuestos a riesgos como la deshidratación y la depredación. Es así como los atributos observados en la morfología de la superficie del corion, se relacionan a las propiedades fisiológicas requeridas por el embrión para enfrentar estas condiciones ambientales (Mazzini 1978). La forma general de los huevos en Tettigoniidae puede ser desde aplanada y discoidal, hasta globosa y se relaciona con la forma del ovipositor que las hembras utilizan para manipular el sustrato de ovipostura (suelo, vegetales vivos o muertos en tallos, corteza, flores, frutos, etc.) (Gwynne 2001). La superficie del huevo puede ser desde suave y sin diseños hasta rígida y con complejos esculpidos derivados de las células foliculares. Éstas modifican su patrón en torno a las micrópilas, las que se presentan en número variable sobre la superficie ventral, desplazadas sub apicalmente hacia el polo posterior, por lo que identificarlas permite ubicar las coordenadas del huevo (Hartley 1964).

En los Nedubini el ovipositor presenta forma de sable alargado, con denticulaciones variadas en el margen de las valvas y en algunos casos en la zona lateral, estas denticulaciones se desarrollan fundamentalmente en su extremo distal (Rentz 1985). En observaciones de campo y laboratorio sobre los cuatro géneros tratados en este estudio hemos observado que la ovipostura ocurre en el suelo, donde la longitud del ovipositor es determinante al momento de alcanzar un estrato específico (observación personal).

La tribu Nedubini Gorochov, 1988, se compone de 20 géneros y 82 especies, distribuidas mayoritariamente en ambientes de aridez en Australia y Tasmania; América del norte, California; y América del Sur en Chile y Argentina (OSF 2013). En Chile se presentan los géneros: Apteropedetes Rentz, 1979 con una especie, Barraza Kocak \& Kelmal, 2008 (antes Calodectes Rentz \& Gurney, 1985) con una especie, Platydecticus Chopart, 1951 con 15 especies, Falcidectes Rentz \& Gurney, 1985 con dos especies y Xyrdectes Rentz \& Gurney, 1985 con dos especies. Su distribución ha sido señalada en Elgueta et al. (1999). Los rasgos diagnósticos de géneros y especies se soportan fundamentalmente en la morfología genital de ambos sexos, y han sido estudiados en la revisión de Rentz \& Gurney (1985), donde los huevos son omitidos y la distribución de los taxa se presenta alopátrica en su mayoría. Sin embargo, recientes colectas del autor y otras depositadas en el Museo Nacional de Historia Natural de Santiago (MNHN), muestran superposición de los rangos de distribución de las especies y una mayor variabilidad de los rasgos de diagnosis. En este nuevo escenario se requiere explorar nueva evidencia, para discriminar especies. Lo anterior, dado que gran parte de la morfología externa presenta rasgos crípticos, lo que se hace particularmente evidente en las hembras del género Platydecticus.
Dada la escases de antecedentes sobre morfología de huevos en los Tettigoniidae de la región andina de América del Sur y la utilidad potencial que se ha señalado en la literatura, el objetivo de este estudio es describir y comparar la microestructura del corion de los huevos, para cuatro géneros de Nedubini presentes en Chile mediante las técnicas de microscopía electrónica de barrido (SEM).

\section{MATERIALES Y METODOS}

Los huevos aquí examinados se obtuvieron siguiendo dos metodologías: a) desde oviposturas de especímenes en cautiverio, recolectados como ninfas o imagos y mantenidos en condiciones de laboratorio junto a placas con arena como sustrato de ovipostura, los huevos fueron conservados en etanol de $70 \%$; b) desde disección de hembras grávidas conservadas en etanol de 70\%. La procedencia del material se detalla junto a cada descripción. La observación de la morfología general, color, medidas y disecciones fueron realizadas en lupa estereoscópica Nikon con oculares de 10X y objetivos (zoom) de $0,7 \mathrm{X}$ a $3 \mathrm{X}$, con reglilla incorporada al ocular, las fotografías tomas con cámara digital fueron analizadas con el software Motic Images Plus 2.0; la observación con SEM fue realizada con microscopio electrónico de barrido Hitachi TM3000.

\section{RESULTADOS}

DESCRIPCIÓN DE HUEVOS

Barraza crybeloplatus (Rentz \& Gurney 1985)

281 huevos desde 5 individuos en cautiverio, oviposturas desde el 30 de diciembre al 15 de febrero del 2002; Chile, Limarí, Socos, col. A. Vera.

Medidas promedio para $\mathrm{n}=30$, Rango en paréntesis: Largo 3,18mm (2,73-3,66); ancho máximo 1,2 (1-1,37).

Coloración del huevo: pardo oscuro, en algunos con los polos amarillentos; de corion grueso y resistente. De forma elipsoidal, con los polos redondeados, esculpido con celdas uniformes en tamaño y distribución (Fig. 1). Celdas coriónicas redondeadas, poco profundas, con paredes de margen irregular (Fig. 2). Micrópilas en número variable distribuidas en filas sub apicales (Fig. 3), cada una constituye un tubo cilíndrico elevado y dirigido medialmente (Fig. 4).

Xyrdectes fuscescens (Blanchard 1851):

8 huevos desde un individuo en cautiverio, ovipostura 7 de abril de 2004; Chile, San Antonio, Pelancura, col. A. Vera.

Medidas promedio para $\mathrm{n}=8$, Rango en paréntesis: Largo 5,8mm (5,36-6,18); ancho máximo 1,5mm (1,25-1,76).

Coloración: gris uniforme; de corion grueso. De forma fusiforme con los polos redondeados, esculpido con celdas uniformes en la región media, y de mayor tamaño en los 
extremos (Figs. 5 y 6). Celdas coriónicas poliédricas (pentagonales y hexagonales), profundas, con paredes planas de margen anguloso (Fig. 7). Micrópilas distribuidas en verrugas agrupadas en dos tripletes o pares ubicadas a un cuatro del extremo polar, las aberturas se encuentran en el margen de la verruga en número variable (Fig. 8).

\section{Falcidectes divisus Rentz \& Gurney 1985}

8 huevos desde 3 individuos en cautiverio, oviposturas 05 a 10 de marzo de 2011; Chile, Petorca, Horcón, col. A. Vera. Medidas promedio para $n=8$, Rango en paréntesis: Largo 5,01mm (4,87-5,32); ancho máximo 1,64mm (1,56-1,79) Coloración: gris uniforme, de corion grueso. De forma fusiforme con los polos redondeados, esculpido con celdas uniformes en la región central, y de mayor tamaño en los extremos (Fig. 9). Celdas coriónicas poliédricas, poco profundas, con paredes convexas de márgenes redondeados (Fig. 10). Micrópilas distribuidas en verrugas agrupadas en tripletes o pares ubicadas a un cuarto del extremo polar, las aberturas se encuentran en el margen de la verruga en número variable (Fig. 11).

Platydecticus robertsi Rentz \& Gurney 1985:

4 huevos, desde disecciones de cuatro individuos respectivamente; Chile, Santiago, Lagunillas, 25-feb-2011. Col. A. Vera.

Medidas n=1: Largo 2,8 mm; ancho máximo 1,15

Coloración: blanco uniforme, de corion delgado y frágil. De forma fusiforme con los polos redondeados, esculpido con celdas uniformes y regularmente distribuidas (Fig. 12). Celdas coriónicas pentagonales y hexagonales con paredes convexas y globosas, elevadas independientemente, centro convexo tan protuberante como la pared (Fig. 13). Micrópilas escasas (6 a 8) distribuidas en pares a un cuarto del extremo polar, las aberturas se encuentran en tubos cónicos, pegados a la pared y de superficie ranurada longitudinalmente (Fig. 14).
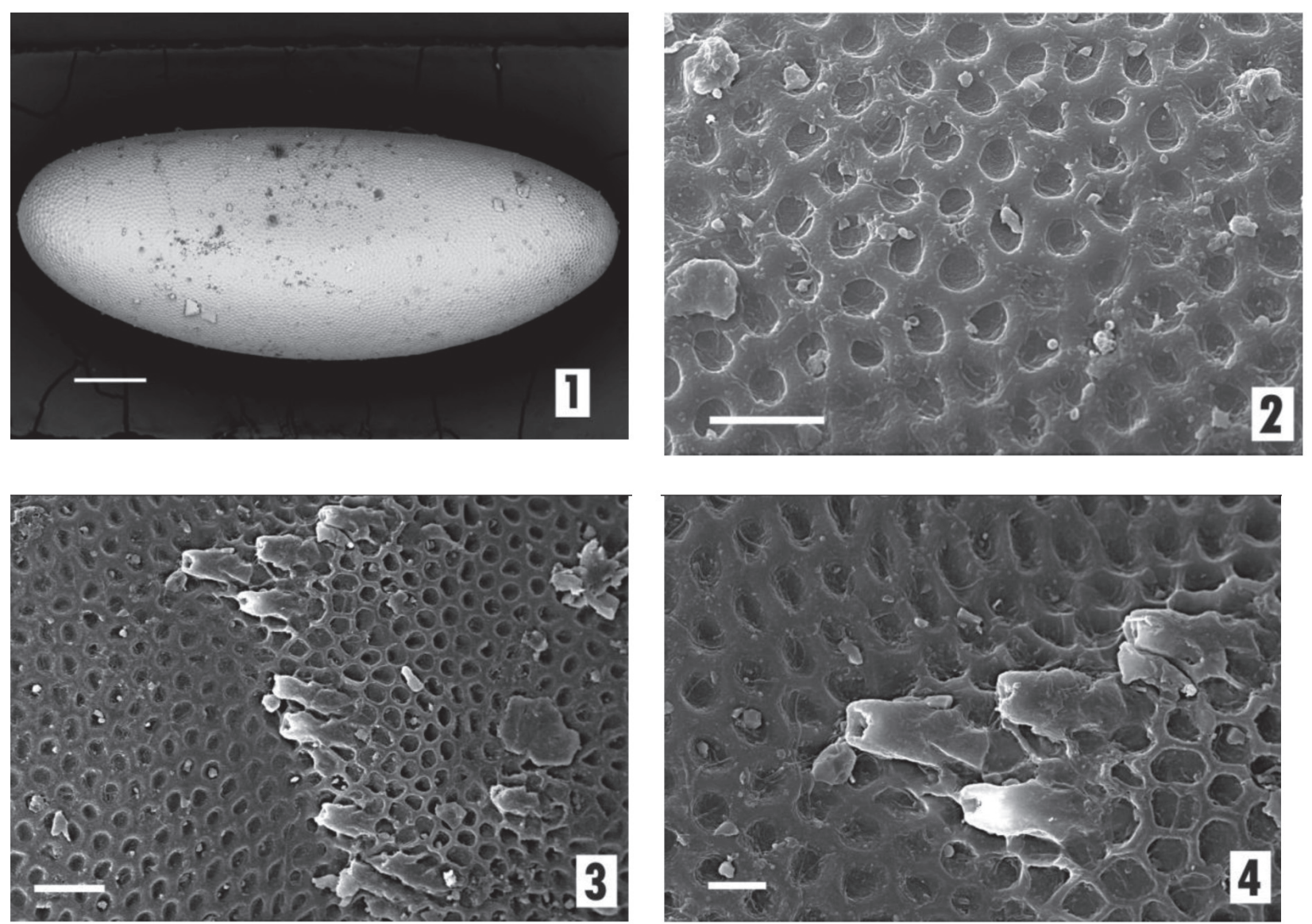

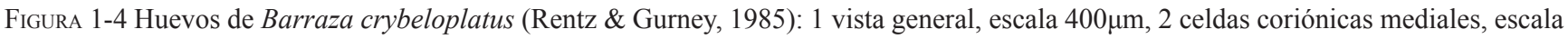
$40 \mu \mathrm{m}, 3$ fila de micropilas, escala $40 \mu \mathrm{m}, 4$ tubos micropilares, escala $20 \mu \mathrm{m}$.

FiguRE 1-4 Barraza crybeloplatus (Rentz \& Gurney, 1985) eggs: 1 general view, scale $400 \mu \mathrm{m}, 2$ chorionic cells medial, scale $40 \mu \mathrm{m}, 3$ micropylar line, scale $40 \mu \mathrm{m}, 4$ micropyles tube, scale $20 \mu \mathrm{m}$. 


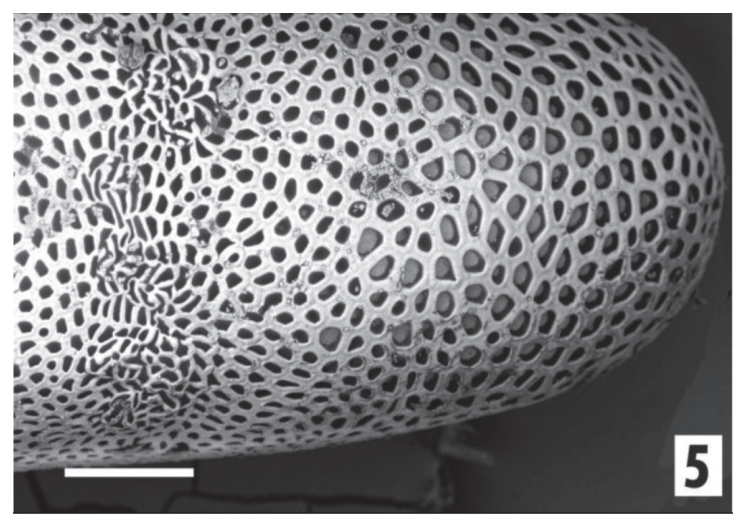

FigURA 5 grupo de verrugas micropilares en Xyrdectes fuscensens (Blanchard, 1851), escala $200 \mu \mathrm{m}$.

FigURE 5 Xyrdectes fuscensens (Blanchard, 1851), micropyles wart group, scale $200 \mu \mathrm{m}$.

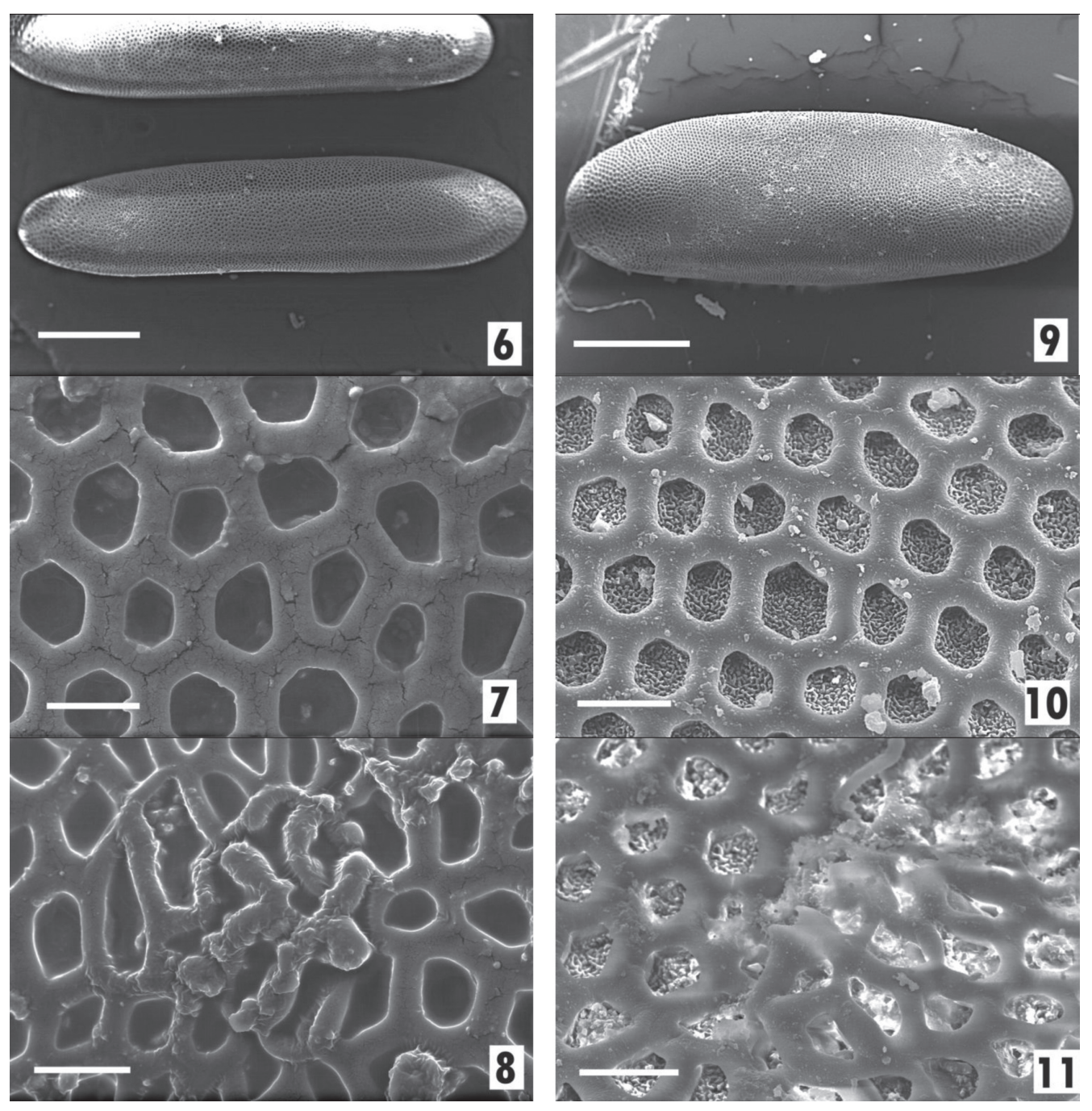

Figura 6-8 huevos de Xyrdectes fuscensens (Blanchard, 1851), 9-11 huevos de Flacidectes divisus Rentz \& Gurney 1985: 6, 9 vista general, escala $1 \mathrm{~mm}, 7,10$ celdas coriónicas mediales, escala $40 \mu \mathrm{m}, 8,11$ verrugas micropilares, escala $40 \mu \mathrm{m}$.

Figure 6-8 Xyrdectes fuscensens (Blanchard, 1851) eggs, 9-11 Flacidectes divisus Rentz \& Gurney 1985 eggs; 6, 9 general view, scale $1 \mathrm{~mm}, 7,10$ chorionic cells medial, scale $40 \mu \mathrm{m}, 8,11$ micropyles wart, scale $40 \mu \mathrm{m}$. 
Platydecticus onax Rentz \& Gurney 1895

3 huevos desde 3 individuo en cautiverio respectivamente, oviposturas entre el 30 de diciembre al 23 de enero del 2008; Chile, Limarí, Socos, col. A. Vera.

Medidas promedio para $n=3$, Rango en paréntesis: Largo $3,49 \mathrm{~mm}(3,25-3,85)$; ancho máximo 1,45mm $(1,39-1,52)$

Coloración blanco uniforme, de corion grueso y resistente. De forma Fusiforme, con los polos redondeados, de superficie rugosa, sin celdas distinguibles (Fig. 15). Superficie coriónica con tabiques de forma variada globosos, superficialmente redondeados y suaves, trabeculados hacia su base (Fig. 16). Micrópilas escasas (4 a 6) distribuidas en grupos (tripletes) cerca del extremo polar, las aberturas se encuentran en tubos dilatados y elevados (Fig. 17).

\section{Platydecticus pheroxiphus Rentz \& Gurney 1985}

164 huevos desde 30 individuos en cautiverio, oviposturas entre el 30 de diciembre al 15 de febrero de 2003; Chile, Limarí, Socos, col A. Vera.

Medidas promedio para $n=30$, Rango en paréntesis: Largo 2,92mm (2,42-3,21); ancho máximo 1,33mm $(0,83-1,33)$.

Coloración gris con manchas más oscuras de forma irregular, de corion suave y blando. De forma fusiforme, con los polos redondeados, de superficie suave sin celdas distinguibles
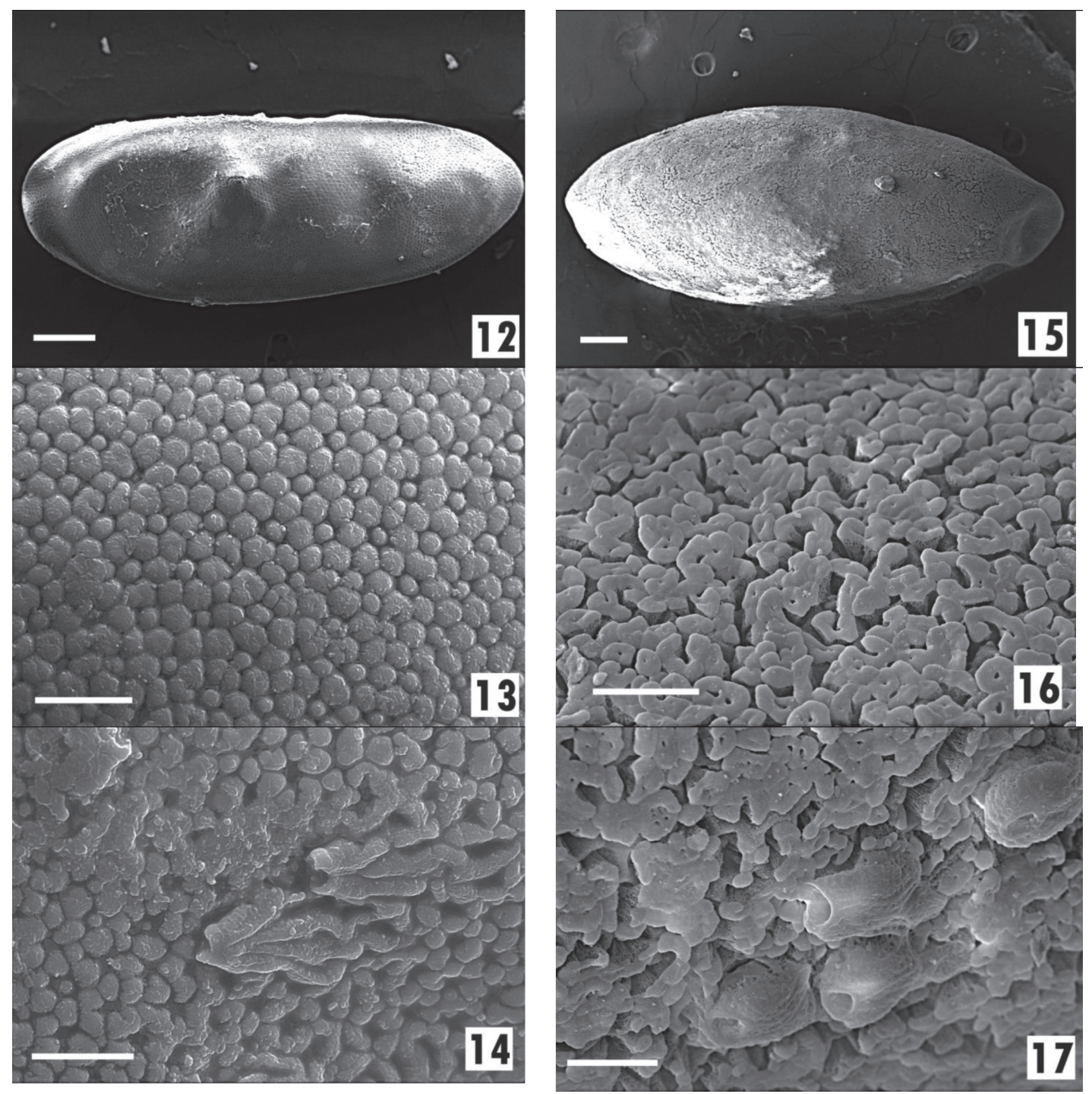

Figura 12-14 huevos de Platydecticus robertsi Rentz \& Gurney 1985, 15-17 huevos de Platydecticus onax Rentz \& Gurney 1985: 12,15 vista general, escala $300 \mu \mathrm{m}, 13,16$ celdas coriónicas mediales, escala $40 \mu \mathrm{m}, 14,17$ tubos micropilares, escala $40 \mu \mathrm{m}$.

FIGURE 12-14 Platydecticus robertsi Rentz \& Gurney 1985 eggs, 15-17 Platydecticus onax Rentz \& Gurney 1985 eggs; 12,15 general view, scale $300 \mu \mathrm{m}, 13,16$ chorionic cell medial, scale $40 \mu \mathrm{m}, 14,17$ micropyles tube, scale $40 \mu \mathrm{m}$. 
(Fig. 18). Corion cubierto de tabiques compactos de forma irregular, de superficie plana y lisa, trabeculados hacia su base. El diseño impide el reconocimiento de celdas (Fig.19). Micrópilas escasas distribuidas en pares a un cuarto del extremo polar, las aberturas se encuentran en tubos cónicos, pegados a la pared y de superficie ranurada longitudinalmente (Fig. 20).

\section{Platydecticus sp.}

1 huevo desde 1 individuo en cautiverio, ovipostura el 30 de diciembre de 2002; Chile, Limarí, Socos, col A. Vera. Medidas n=1: Largo 2,5mm; ancho máximo 1,15mm.
Coloración blanco, de corion suave y blando. De forma piriforme con polos redondeados, superficie esculpida con celdas distribuidas uniformemente, salvo por la región próxima a las micrópilas, donde presentan un mayor tamaño (Fig. 21). Celdas coriónicas irregulares, con sus paredes con forma de tabiques independientes, de superficie redondeada y lisa, trabeculados hacia la base, el centro es irregular y esta elevado al mismo nivel que la pared (Fig. 22). Micrópilas escasas, distribuidas en grupos o solitarias a un cuarto del extremo polar menor, las aberturas se encuentran en tubos cónicos, elevados y de superficie ranurada longitudinalmente (Fig. 23).
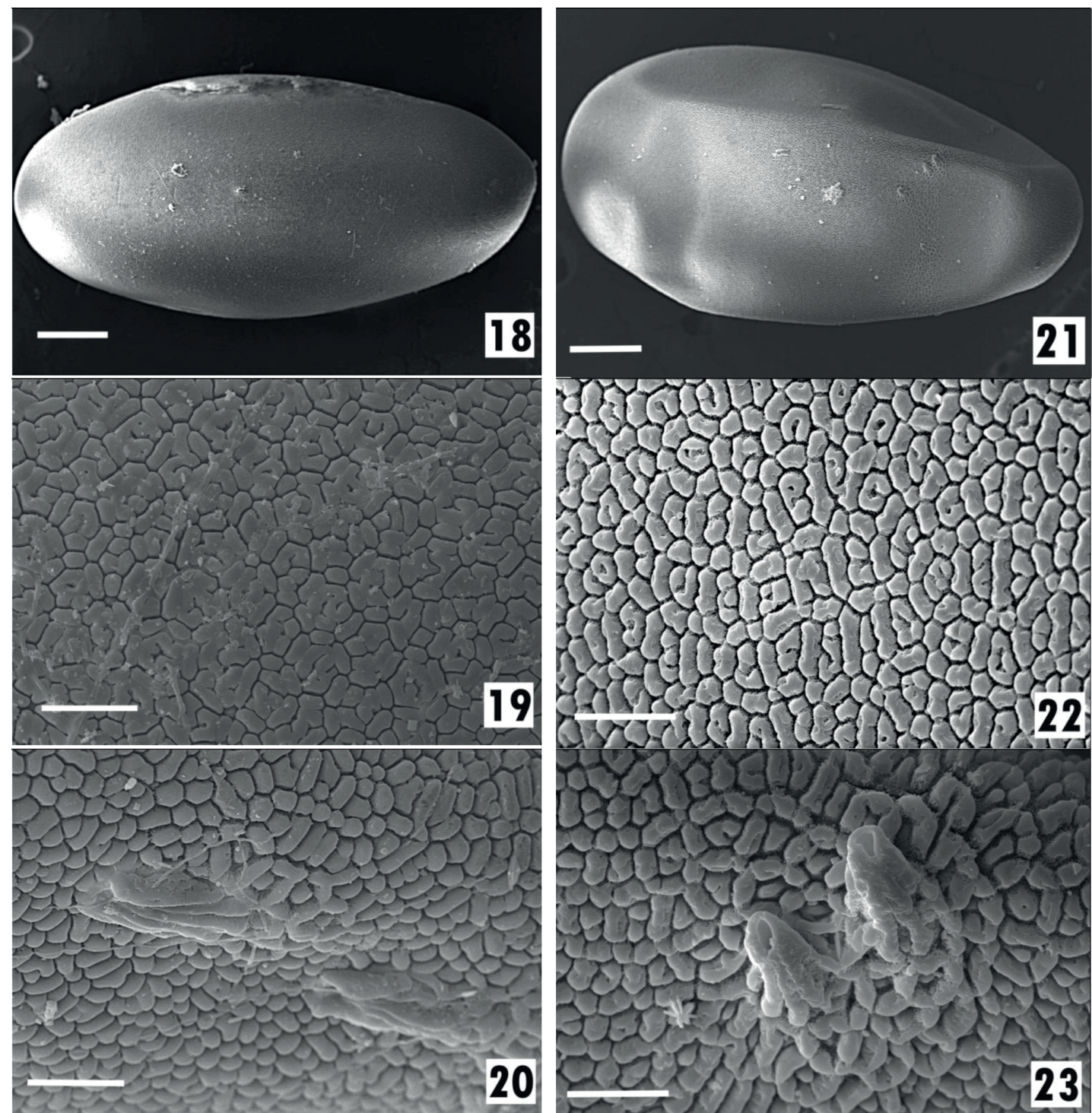

Figura 18-20 huevos de Platydecticus pheroxiphus Rentz \& Gurney 1985, 21-23 huevos de Platydecticus sp.: 18, 21 vista general, escala $300 \mu \mathrm{m}, 19,22$ celdas coriónicas mediales, escala $40 \mu \mathrm{m}, 20,23$ tubos micropilares, escala $40 \mu \mathrm{m}$.

Figure 18-20 Platydecticus pheroxiphus Rentz \& Gurney 1985 eggs, 21-23 Platydecticus sp. eggs: 18, 21 general view, scale $300 \mu$ m, 19 , 22 chorionic cell medial, scale $40 \mu \mathrm{m}, 20,23$ micropyles tube, scale $40 \mu \mathrm{m}$. 


\section{DISCUSIÓN}

En cuanto a las metodologías de obtención de huevos, la más eficiente es la conservación en cautiverio de hembras hasta la ovipostura, su inconveniente es la colecta de material vivo. Alternativamente la disección de hembras grávidas, preferentemente conservadas en etanol, dio buenos resultados, su inconveniente es el diagnóstico adecuado del estado de gravidez, para obtener huevos completamente formados. En Platydecticus mediante disecciones solo fue posible obtener un huevo completamente desarrollado en cada hembra.

El único género de Nedubini presente en Chile que no se incorporó a este estudio fue el de la especie Apteropedetes anaesegalae (Gurney \& Liebermenn 1975), genero monotípico de distribución altoandina, conocido por escasos registros y su presencia casi nula en colecciones nacionales, inicialmente fue descrito para Argentina, Mendoza, Cerro Aconcagua a 4250msnm; holotipo depositado en Washington (Gurney \& Liebermann 1975), dos paratipos en el Museo de la Plata-Argentina (Donato 2000), en Chile se ha registrado para el Volcán San José a 4.500msnm, un macho depositado en ANIC Camberra (OSF), mientras que en MNHN-Santiago de Chile se encuentra un espécimen hembra ingrávida, proveniente de Cerro El Morado, Región Metropolitana, su estado hace imposible la extracción de huevos.

En cuanto a la discriminación genérica de los huevos estudiados, la combinación de la talla y la morfología de las celdas coriónicas facilita el reconocimiento de los cuatro géneros, sin embargo, se hace evidente la proximidad de Xyrdectes y Falcidectes, quienes comparten rasgos como: 1.- la forma poliédrica de las celdas, diferenciándose en la profundidad y la forma de su pared ,2.-las micrópilas reunidas en verrugas y 3.- su rango de talla, siendo los más largos y separándose por $1,02 \mathrm{~mm}$ de los restantes géneros. Por otra parte los géneros Barraza y Platydecticus presentan: 1.micrópilas tubulares y 2.- comparten un rango de talla entre 2,73 a 3,66mm, donde Barraza se superpone con tres de las especies de Platydecticus estudiadas. Barraza presenta filas de abundantes micrópilas y celdas coriónicas circulares, de paredes lisas, mientras que Platydecticus presenta escasas micrópilas, y celdas que varían notablemente permitiendo discriminar cada una de las especies aquí incluidas.

La similitud en talla de los huevos de Barraza y Platydecticus no es trivial, las especies de Platydecticus son las más pequeñas de Nedubini, por lo que era esperable la presencia de huevos diminutos, pero B. crybeloplatus puede ser tan o más grande que otras especies de Xyrdectes y Falcidectes. La relación de largo corporal y huevo en Barraza es 6,94 y en relación a su ovipositor es 8,84 , mientras que las de
P. onax son respectivamente 3,4 y 1,9 , siendo esta una de las especies de mayor tamaño dentro del género. La discordancia que resulta en Barraza provoca una serie de preguntas sobre la evolución de la talla, en cuanto a que el evento ocurrido fue la reducción del huevo o el aumento de tamaño de los imagos, en el linaje que dio origen a Barraza. En este escenario es interesante considerar además el número máximo de huevos que produce cada individuo, es probable que en los pequeños Platydecticus sea mucho menor que en Barraza, entonces cual sería la incidencia de los compromisos entre estos parámetros reproductivos de estos taxa. Estas preguntas históricas podrían ser abordadas en un posterior estudio de método comparado filogenético.

Finalmente los resultados expuestos han permitido descubrir nuevos caracteres de discriminación para taxa que en su mayoría presentan rasgos crípticos en su morfología externa, y son auspiciosos si se les incorporan en estudios con mayor cobertura de especies ya sea tanto con fines de discriminación taxonómica como para estudios de sistemática.

\section{CONCLUSIONES}

La exploración con SEM de la morfología coriónica, realizada por primera vez en este estudio para Tettigoniinae del cono Sur de Sudamérica, ha resultado en la obtención de nuevos caracteres para el reconocimiento de géneros $\mathrm{y}$ especies de Nedubini presentes en Chile; además los rasgos del corion y la morfología de las micrópilas ayudarían en particular, a discriminar las especies de Platydecticus que coexisten y presentan hembras sinmorficas pobres en rasgos de diagnosis; finalmente a partir de los resultados expuestos se hace evidente una divergencia entre la talla de los imagos y huevos en Barraza respecto de las otras especies, lo que requiere diseñar nuevas investigaciones.

\section{AGRADECIMIENTOS}

Se agradece al Museo Nacional de Historia Natural de Santiago de Chile, Sección Entomología por facilitar la consulta de colecciones, y en particular al Sr. Mario Elgueta por facilitar bibliografía y comentarios de apoyo durante la realización de este estudio. A los evaluadores anónimos del manuscrito. Al proyecto APIS 02-12 de la Universidad Metropolitana de Ciencias de la Educación.

\section{BIBLIOGRAFIA}

Dominguez, E., Molineri, C., Pescador, M. Hubbard, M. \& Nieto, C. 2006. Ephemeroptera of South America. A.B.L.A Volume 2, Pensoft Sofia-Moscow 1644pp. 
Donato, M. 2000. Los ejemplares tipo de Orthoptera depositados en el Museo de la Plata. Revista de la Sociedad Entomológica Argentina 59(1-4): 61-84.

Elgueta, M., Camousseight, A. \& Carbonell, C.S. 1999. Catálogo de Orthoptera (Insecta) de Chile. Publicación Ocasional, Museo Nacional de Historia Natural, Chile, 54: 1-60.

Ganguly, A., Malakar, C. , Anand, H., Das, S., Das, A. \& Haldar, P. 2008. Scanning electron microscopy of egg-surface sculpturing of two common Indian shorthorn grasshoppers (Orthoptera, Acrididae). Journal of Orthoptera Research 17(1): 97-100.

Gwynne, D.T. 2001. Katydids and Bush-Crickets Reproductive Behavior and Evolution of the Tettigoniidae. A volume in the Cornell series in arthropod biology, edited by J. Alcock, 317p. Comstock Publishing Associates a Division of Cornell University Press, Ithaca and London.

Hartley, J.C. 1964. The estructure of the eggs of the British Tettigoniidae (Orthoptera). Proceedings of the Royal Entomological Society of London 39(7-9): 111-117.

INGRISCH, S. 1984. The influence of environmental factors on dormancy and duration of egg development in Metrioptera roeseli (Orthoptera: Tettigoniidae). Oecologia (Berlin) 61: 254-258.

INGRISCH, S. 1985. Effect of hibernation length on termination of diapauses in European Tettigoniidae (Insecta: Orthoptera). Oecologia (Berlin) 65:376-381.

INGRISCH, S. 1986a. The Plurennial life cycles of the European Tettigoniidae (Insecta: Orthoptera). 1. The effect of the temperature on embryonic development and hatching. Oecologia 70: 606-616.

INGRISCH, S. 1986b. The Plurennial life cycles of the European Tettigoniidae (Insecta: Orthoptera). 2. The effect of photoperiod on the induction of an initial diapause. Oecologia 70: 617-623.

INGRISCH, S. 1986c. The Plurennial life cycles of the European Tettigoniidae (Insecta: Orthoptera). 2. The effect of drought and the variable duration of the initial diapause. Oecologia 70: 624-630.

INGRISCH, S. 1987a. Oxygen consumption by developing and diapausing eggs of Eupholidoptera smyrnesis (Orthopetara: Tettigoniidae). Journal Insects Physiology 33(11): 861-865.
INGRISCH, S. 1987b. Effect of photoperiod on the maternal induction of an egg diapauses in the grasshopper Chorthippus bornhalmi. Entomologia Experimentalis et Applicata 45:133-138.

Kocak, A.O. \& M. Kemal. 2008. Remplacement Names Among the Genus And Family Group taxa in Orthoptera. Miscellaneous Papers Centre for Entomological Studies Ankara 141: 1-8.

MAzZINI, M. 1978. Amino acid analysis and morphology of the egg shell of Tettigonia viridissoima L. (Orthoptera: Tettigoniidae). International Journal of Insect Morphology and Embryology 7(3): 205-214.

OSF. 2013. Eades, D.C.D. \& D. OtтE. Orthoptera Species File Online. URL: http://OrthopteraSpeciesFile.org. Accesado junio 30, 2013

Rentz, D.C.F., Ning Su, Y. \& Ueshima,N. 2007. Studies in Australian Tettigoniidae. A New Genus of Listroscelidine Katydids From Northern Australia (Orthoptera: Tettigoniidae; Listroscelidinae). Transaction of the Entomological Society 133(3-4): 279-296.

Rentz, D.C.F. \& GuRnEy, A.B. 1985. The shield-backed Katydids of South America (Orthoptera: Tettigoniidae, Tettigoniinae) and a new tribe of Conocephalnae with genera in Chile and Australia. Entomologica Scandinavica 16:69-119.

Stark, B., Froehlich, Cl. \& Zúñiga, M.C. 2009. South American stoneflies (Plecoptera). A.B.L.A volumen 5, Pensoft SofiaMoscow 154pp.

Tuck, J.C. \& Sмith, R.C. 1939. Identification of the eggs of mid-western grasshoppers by the chorionic sculpturing. Technical Bulletin $n^{\circ} 48$, Agricultural experiment station, Kansas State College of Agriculture and Applied Science, Manhattan, Kansas 39pp.

Webber, B. L., Rentz, D.C.F., Ueshima, N. \& Woodrow, I. E. 2007. Leucopodoptera eumundii, a new genus and species of katydid from the tropical rainforests of North Queensland, Australia (Orthoptera: Tettigoniidae: Phaneropterinae: Holochlorini). Transactions of the American Entomological Society 133(3 \& 4): 279-296.

Zompro, O. 2004. Revision of the genera of the Areolatae, including the status of Timema and Agathemera (Insecta, Phasmatodea). Abhandlungen des Naturwissenschaftlichen Vereins in Hamburg, (NF) 37:3-327 